\title{
A MODEL OF INTEGRATED MARKETING COMMUNICATION ORIENTATION: THE MEXICAN FIRMS CASE
}

\author{
Laura Esparza-Martínez Universidad de Monterrey, México \\ Marco Vinicio Gómez-Meza, Universidad Autónoma de Nuevo León, México
}

\begin{abstract}
The behaviour of a sample of 356 small, medium and large sizes Mexican firms (SMLFs) were tested in the Integrated Marketing Communications (IMC) construct and its relation with Market Orientation (MO), Brand Performance (BP) and Financial Performance (FP). The objective was to explore the relation of the mentioned constructs in a group of Mexican firms and the possible mediating effect that being IMC oriented will have in their effectiveness. A set of multivariate techniques were applied to make the testing and the results suggested that the orientation to IMC is a needed step to reach Brand performance and through it to achieve Financial Performance, that the Mexican firms will be beneficiated of the use of the resulted model because the relations probed to be significant and a good adjustment of fit of model was obtained, these support the need of doing an assessment of the firm in the different constructs involved in the model in order to define its current situation, the firms under study were SMLF's as have been established small and medium size are the must abundant in this country and usually they are managed by their owners, they are the ones that could use this knowledge for their benefit.

Finally $\mathrm{n}$ order to convince owners and/or managers of an organization to work on the implementation of new strategies, usually the best way is through a forecast that show the benefits that will be obtained of the implementation, if as the results suggest as seen in the final model, Market Orientation is an antecedent to Integrated Marketing Communications orientation, and going through this orientation is possible to achieve Brand Performance and finally to reach Financial Performance these will be the argument to recommend the assessment of the current situation of the firm, the knowledge will help to take it the right way and define the actions that based on the specific mission and vision of the firm will help it to fulfil its goals. If the firm is already in the desired position, the assessment will be very useful to stress the actions that allow it to maintain the position. Depending on the result, will be the decision to be made in order to improve their Marketing practices and to promote the implantation of the appropriate ones that support their marketing strategies.
\end{abstract}

References available upon request 